Discussion Paper No. 13-043

The Strategic Use of Fuzziness in Patent Specifications

Alexandra K. Zaby and Diana Heger

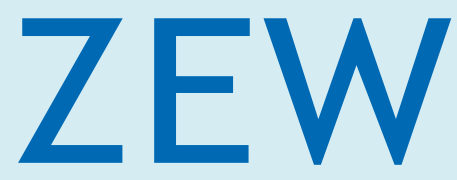

Zentrum für Europäische Wirtschaftsforschung $\mathrm{GmbH}$

Centre for European Economic Research 
Discussion Paper No. 13-043

\title{
The Strategic Use of Fuzziness in Patent Specifications
}

\author{
Alexandra K. Zaby and Diana Heger
}

Download this ZEW Discussion Paper from our ftp server:

http://ftp.zew.de/pub/zew-docs/dp/dp13043.pdf

Die Discussion Papers dienen einer möglichst schnellen Verbreitung von neueren Forschungsarbeiten des ZEW. Die Beiträge liegen in alleiniger Verantwortung der Autoren und stellen nicht notwendigerweise die Meinung des ZEW dar.

Discussion Papers are intended to make results of ZEW research promptly available to other economists in order to encourage discussion and suggestions for revisions. The authors are solely responsible for the contents which do not necessarily represent the opinion of the ZEW. 


\section{Non-technical summary}

For providing protection for intellectual property, patent law requires the comprehensive description of the invention, its making and using. The goal of this disclosure requirement is to provide newly generated knowledge to the public, and thus, to foster technological progress. Since a patent affects competition on the market for ideas and the product market, the patenting decision incorporates a strategic decision. Economic literature commonly ignores that the extent to which a patent actually discloses information about the invention itself is a strategic decision of the applicant.

In this paper, a three-stage theoretical model illustrates the decision process of a patent applicant. A follow-on invention can successfully be made by a potential follower who bases his research on the original patent. The applicant can choose between either a fuzzy or a distinct formulation in the patent specification whereas he has to take into account two countervailing effects: On the one hand, a fuzzy description decreases the usability of a patent for the followers as it increases their research costs and at the same time their probability of success to achieve the follow-on invention. On the other hand, fuzziness decreases the granting probability. This model can also be linked to the quality of patent examination. Even if the quality is high (i.e. the granting probability for a fuzzy patent is lower than the one for a distinct patent) some cases exist for which fuzzy description is more profitable for the inventor despite the higher risk of not receiving the grant. These results allow careful recommendations for policymakers and patent offices. If the goal of patent policy is an appropriate incentive system which yields clear and precise patent descriptions in order to foster technological progress, the granting probability should be strongly reduced for fuzzy specifications. A possible way to achieve this could be the request for a proof of concept and/or experimentation data. This may improve the quality of examination and the quality of knowledge disclosure via patents. Such a procedure would be analogous to the publication procedures of scientific results, for which a precise description of data, measurement and methods is required. 


\section{Das Wichtigste in Kürze}

Ein Ziel von Patenten ist, intellektuelles Eigentum zu schützen. Für die Gewährung des Schutzes ist es nach dem Patentgesetz erforderlich, die Erfindung und ihre Einsatzmöglichkeiten umfassend zu beschreiben. Diese Offenlegung soll dazu beitragen, neues Wissen der Öffentlichkeit zugänglich zu machen und somit den technologischen Fortschritt voranzutreiben. Die Anmeldung eines Patents hat aber auch eine strategische Komponente, da ein Patent den Wettbewerb auf den Technologie- und Produktmärkten beeinflusst. Allerdings wird in der Literatur oft ignoriert, dass bereits die Formulierung einer Patentanmeldung eine strategische Entscheidung ist.

In diesem Papier wird mit Hilfe eines dreistufigen theoretischen Modells der Entscheidungsprozess eines Patentanmelders analysiert. Eine nachfolgende Erfindung kann auch erfolgreich von einem Dritten getätigt werden, dessen Forschung auf dem ursprünglichen Patent aufsetzt. Der Anmelder entscheidet, ob er das Patent präzise oder ungenau spezifiziert. Hierbei muss er zwei gegenläufige Effekte gegeneinander abwägen: Einerseits senkt eine unpräzise Formulierung die Nutzbarkeit des Patents für Dritte, indem es deren Forschungskosten erhöht und gleichzeitig ihre Erfolgswahrscheinlichkeit für die nachfolgende Entdeckung senkt. Andererseits senken Ungenauigkeiten die Wahrscheinlichkeit einer Patenterteilung. Das Modell kann auch im Hinblick auf die Qualität der Patentprüfung im Erteilungsverfahren interpretiert werden. Selbst wenn die Qualität der Patentprüfung hoch ist (d.h. die Ablehnungswahrscheinlichkeit für eine unpräzise formulierte Patentanmeldung ist höher als für eine präzise formulierte), gibt es Fälle, in denen Ungenauigkeiten in der Formulierung für den Anmelder profitabel sind trotz der niedrigeren Erteilungswahrscheinlichkeit.

Die Politikempfehlung, die sich aus den Ergebnissen des Modells ergibt, ist, dass die Wahrscheinlichkeit der Erteilung eines Patents im Falle einer nicht ausreichend präzisierten Beschreibung stark reduziert werden muss, um den technologischen Fortschritt zu fördern. Um dies zu erreichen, könnte die Patenterteilung an die Bedingung der Verfügbarkeit von (funktionierenden) Prototypen oder Daten von Versuchsdurchführungen gekoppelt werden. Dies würde sowohl die Qualität der Patentprüfung als auch die Qualität der Offenlegung durch Patente verbessern. Dieses Vorgehen wäre analog zum Publikationsprozess von wissenschaftlichen Ergebnissen, in dem eine genaue Beschreibung der verwendeten Daten, Messund Analyseverfahren verlangt wird. 


\title{
The Strategic Use of Fuzziness in Patent Specifications
}

\author{
Alexandra K. Zaby ${ }^{\dagger *}$ and Diana Heger ${ }^{\ddagger *}$
}

\begin{abstract}
Innovators seek to protect their intellectual assets by patenting them, at the same time trying to avoid any disclosure of critical knowledge. Given that a patent specification has to include a clear description of the patented matter so that anybody "skilled in the art" is enabled to reproduce the invention, the non-disclosure intention seems contradictory to patent law. This paper provides a model identifying the incentives for firms to deliberately obscure their inventive knowledge in a patent specification.
\end{abstract}

Keywords: patent specification, disclosure requirement, strategic firm behavior, fuzzy patents

JEL Classifications: O31, O34, L24, D21

${ }^{\dagger}$ University of Tuebingen, Faculty of Economics, Mohlstraße 36, D-72074 Tuebingen, Germany. E-mail: alexandra.zaby@uni-tuebingen.de

${ }^{\ddagger}$ Centre for European Economic Research, L7, 1, D-68165 Mannheim, Germany. E-mail: heger@zew.de

*The authors are grateful to Deepak Hedge, Georg Licht, Manfred Stadler as well as the participants of the IIOC 2013 in Bosten for valuable comments and discussions. This publication is the result of a project sponsored within the scope of the SEEK research programme which was carried out in cooperation with University of Tuebingen, Germany, Melbourne University, Australia, and ZEW Mannheim, Germany. All remaining errors are ours. 


\section{Introduction}

The primary motivation of governments for issuing patents is to provide incentives to innovate. Within the innovation process new knowledge is generated which bears some characteristics of a public good. Due to this, the new discovery may be subject to the expropriation of knowledge. A patent is, hence, a tool to transfer new, freely accessible knowledge into a proprietary good. As a consequence, the discovery is protected from expropriation and can be traded like a commodity, i.e. the inventor has the possibility to generate returns from his $R \& D$ activities by either exclusively manufacturing the innovation, by licensing-out, or by selling the intellectual property (IP). Besides this protective effect of patenting, patents are supposed to contribute to a society's knowledge stock through the mandatory disclosure of the invention. ${ }^{1}$ The disclosure requirement in the U.S. is rooted in 35 U.S.C. $\S 112$ which states:

The specification shall contain a written description of the invention, and of the manner and process of making and using it, in such full, clear, concise, and exact terms as to enable any person skilled in the art to which it pertains, or with which it is most nearly connected, to make and use the same, and shall set forth the best mode contemplated by the inventor of carrying out his invention.

The specification shall conclude with one or more claims particularly pointing out and distinctly claiming the subject matter which the applicant regards as his invention.

To be precise, we understand a "patent specification" as including the claims as well as the description of an invention. Necessarily, this relates our approach to the broad literature concerning patent breadth. Our understanding of the impact of fuzziness on patent breadth is that fuzziness blurs a patent's boundaries (see Bessen and Meurer 2009) but does not necessarily broaden them. However, the chance that a fuzzy patent is interpreted wider than a distinct patent by competitors or legal institutions, e.g. courts, may increase with the degree of its impreciseness. At the same time, the indistinct patent specification may lead to the revocation of the patent when it is challenged in court (see Lemley et al. (2005)).

The strategic dimension of patenting is widely acknowledged (see e.g. Hall and Harhoff 2012). We argument that - unraveling the procedure of applying for the patent - the manner in which a patent specification is written itself already constitutes a strategic decision: choosing a fuzzy description of the invention may delay or even hinder the market entry of competitors but has the drawback of decreasing the probability of patent grant. The strategic decision how to write a

\footnotetext{
${ }^{1}$ Whether the disclosed information can be used by competitors without licensing depends inter alia on the patent law's definition of the research use exemption.
} 
patent specification thus depends on the threat of entry by competitors and the probability of receiving a patent grant which both decrease when using a more fuzzy description. ${ }^{2}$

Our paper contributes to the literature on the value of patent disclosure (see e.g. Devlin 2010, Gambardella et al. 2011). The disclosure effect of patenting is intended to foster technological progress. However, legal and economic scholars claim that patent disclosure is only limited. The literature has identified three major reasons for this: First, the technical information contained in patent descriptions is rather scarce. This is mainly attributed to the fact that patent documents are written in a specific, legal language veiling the technical aspects of the discovery (Seymore 2010). Second, as patent disclosure may benefit a patentee's competitors - this is the main explanation why inventors are reluctant to patent their discoveries (see e.g., Cohen et al. 2002 for empirical evidence) - the incentive to patent is highly influenced by the nature of the technology incorporated in an invention: if it is easy to re-engineer, patenting may become more attractive for inventors. Hence, some scholars suspect that applicants omit essential know-how and only disclose that part of the invention which can most easily be re-engineered (Hall and Harhoff 2012). And finally, firms seem to formulate abstract claims in order to expand patent protection to related future inventions. The main difficulty is that abstract claims blur the boundaries of the property right (Bessen and Meurer 2009, Roin 2007). In our paper, the term fuzzy patent includes any of these strategic concealments in patent specifications: the use of a specific "patent language", the patenting of parts of the discovery and abstract claims.

The presented theoretical model analyzes an inventor's decision of how to phrase his patent specification. ${ }^{3}$ A successful inventor faces the tradeoff between a clearly written patent specification with a high granting probability which yields high technology disclosure to competitors, and an imprecise patent description with a low granting probability which mitigates technology disclosure as competitors need additional time to "decode" the fuzzy patent in order to imitate or invent around it.

Specifically, we model a three-stage game along the granting process for patent applications looking at two firms: the innovator who has achieved an invention which he wants to protect with a patent and a (potential) follower who may decide on whether to invest in R\&D to imitate or invent around the patent. In the first stage the innovator decides how precisely to phrase the patent when filing the application. On the second stage, the follower decides whether he would invest in R\&D to enter the market with a copy or a variant of the product. On the third stage, after the patent office decided whether to grant the patent, firms realize

\footnotetext{
${ }^{2}$ Hall and Harhoff 2012 provide a similar argument.

${ }^{3}$ The presented model is inspired by the model presented in Bessen 2005 that focuses on the functioning of patents as a means of technology diffusion.
} 
payoffs according to their respective commercialization strategies.

Our work relates to different approaches within the patent literature. In their seminal paper, Lemley et al. 2005 describe the notion of patents as probabilistic rights that - due to low examination quality - may be found invalid when challenged in court. The presented model takes one step back and proposes that inventors anticipate low examination quality. By obscuring their patent descriptions they try to undermine the intended technology disclosure. We show that in a setting with low examination quality, i.e. the probability that a "fuzzy" patent is granted is nearly as high as the probability that a "distinct" patent is granted, inventors indeed have an incentive to obscure their patent specification.

Our model has a practical bearing. In the case Teva Canada Ltd. v. Pfizer Canada Inc., 2012 SCC 60, the court deemed Pfizer's patent on erectile dysfunction invalid because Pfizer did not indicate which of the two compounds protected by the patent claims was the effective one. Hence, the court agreed that Teva, the prospective producer of a generic medicament, was not provided with a full and concise description of Pfizer's invention and would have needed to conduct further experimentation to re-engineer it. This example shows that even granted patents run the risk of being deemed invalid. In this paper, we focus on the preceding decision of the inventor on how to phrase the patent application. As we aim at understanding the very basic mechanisms that drive the incentives to obscure a patent specification, we ignore the (probably higher) risk of litigation which accompanies a fuzzy patent and leave this issue to future research.

For further anecdotal evidence, we refer to an interview with a R\&D service firm in the area of synthetics. ${ }^{4}$ The $R \& D$ service firm was mandated to develop a new synthetic with specific characteristics by one of the big players in the market for synthetics. As a result, they identified an exact temperature to which the composition has to be heated to reach the favorable characteristics. The interviewee's answer concerning the optimal patenting strategy ${ }^{5}$ was that - as it is mandatory for patents covering chemical compounds to disclose the exact composition of the components - the best way to protect this invention would be to seek protection for a wide range of possible temperatures within which one would still get similar synthetics but with less favorable characteristics.

From the related empirical survey ${ }^{6}$ of 135 small and medium sized enterprises in Germany, we are able to extract a further hint that patent specifications do not necessarily contain enabling knowledge, suggesting that patentees are able to obscure their inventions. In an online survey, innovative firms, which filed a

\footnotetext{
${ }^{4}$ This interview was conducted in the context of a project within the SEEK framework. The topic of this research project is "The Research Use Exemption from Patent Infringement: Boon or Bane?". See seek.zew.de.

${ }^{5}$ As a matter of fact, the R\&D service firm usually does not apply for patent protection as they are mandated to develop new products the proprietary assignation of which is part of the contract concluded with its customer.

${ }^{6}$ See footnote 4 .
} 
patent to protect their invention, were asked to think of an expert skilled in the art who has a perfectly equipped lab; how easy would it be for this expert to re-engineer the patented innovation using the technological information disclosed in the patent specification.

Table 1: Patent Disclosure (Share of firms)

\begin{tabular}{ccccccc}
\hline extremely easy & 2 & 3 & 4 & 5 & 6 & extremely difficult \\
0.118 & 0.212 & 0.153 & 0.200 & 0.141 & 0.118 & 0.059 \\
\hline
\end{tabular}

Source: SEEK survey on research use exemption.

As the above table shows the answers were scattered over a 7-point Likert scale provided to assess the statement, ranging from "extremely easy" to "extremely difficult". These results reveal that firms subjectively assess their patent specification as not so clearly written that another person could easily rebuild the protected invention which provides anecdotal evidence for our argumentation that firms strategically obscure their patent specifications.

The remainder of the paper is organized as follows: Section 2 presents our theoretical model. The three stage game is solved by backward induction, beginning with the analysis of the commercialization payoffs in section 2.1, the research investment decision of the non-patentee firm in section 2.2 and the decision between a fuzzy or a distinct patent specification in section 2.3. Section 3 concludes. Proofs can be found in the Appendix.

\section{The Model}

Suppose risk-neutral firms, of which one, the "innovator" (called the "leader" throughout the rest of the paper), owns an invention which he decided to protect by a patent. His rivals, the "followers", will attempt to enter the market for the innovative product by investing in research to imitate or invent around the (applied for) patent whenever this is feasible for them. In order to enter, followers face research costs which are subject to the phrasing of the leader's patent. For simplicity, we assume that these costs are such that only one rival firm is potentially able to enter. ${ }^{7}$ Both firms interact in a simple three-stage game where the decisions are intertwined with the timing of the patenting process. A simplified timeline of the patenting procedure is depicted in Figure 1.

\footnotetext{
${ }^{7}$ Allowing more than one rival firm entering the market would complicate the model while leaving the overall qualitative results unchanged.
} 


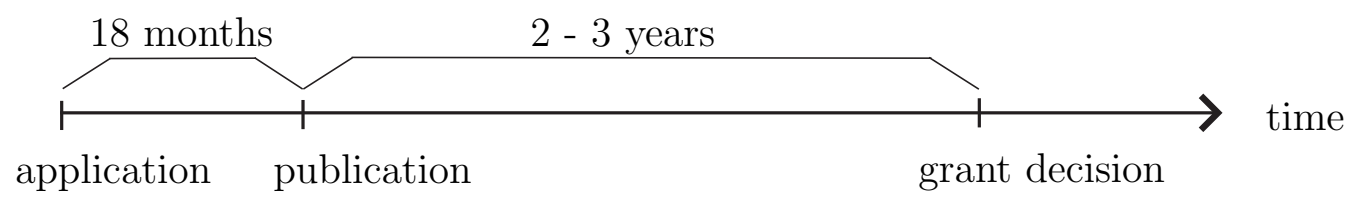

Figure 1: Timing of the patenting process

A patent application process may take several years whereas every patent application is published after 18 months, independently of the progress of the patent examination procedure. Only during the period of the first 18 months the application is kept secret. The time between application and grant decision is on average almost three years for the USPTO (see ?) and more than 4 years for the European Patent Office (see ?).

The decisions of the firms are depicted in Figure 2. First, the leader decides on the phrasing of his patent specification. He can either clearly define the patented matter in the patent specification, i.e. choose a distinct patent, or he may obscure his innovative knowledge in the patent specification, i.e. formulate a fuzzy patent. With the publication of the patent, the follower observes the usefulness of the patent for him and then decides whether to invest in imitating/inventing around the patent or not. His research project is successful with probability $q_{s}, s=f, d$ whereas it $\operatorname{costs} c_{s}, s=f, d$ in any case, success or failure. We assume that the probability of success is higher, if a distinct patent provides easily accessible know how, meaning that $q_{d}>q_{f}$. We further assume that the necessary research investment is lower with a distinct than with a fuzzy patent, $c_{d}<c_{f}$.

Subject to the phrasing of the patent application, the patent office then decides whether the patent is granted or not. 8 A distinct patent application is granted with probability $p_{d}$ while a fuzzy specification is granted with a lower probability, $p_{f}$. After the granting decision, both firms simultaneously realize their respective market entry strategy regarding the innovation. While the follower's market entry depends on his successful inventing around/imitation of the invention, the leader could enter in any case, irrespective of the patent office's decision. Note that market entry does not necessarily mean that the leader commercializes his innovation on the product market, it could also be that he decides to license his patent without marketing it himself. In any case, he chooses the strategy which yields positive payoffs.

\footnotetext{
${ }^{8}$ In reality this grant decision is the final decision in an interaction process between patent authorities and the applicant, during which the phrasing of the patent specification may be modified. For simplicity, we only consider the phrasing of the patent application as decisive for the patent office's granting decision. We are aware of the fact that the patent office requires the fulfillment of the criteria of newness and a sufficient inventive step.
} 


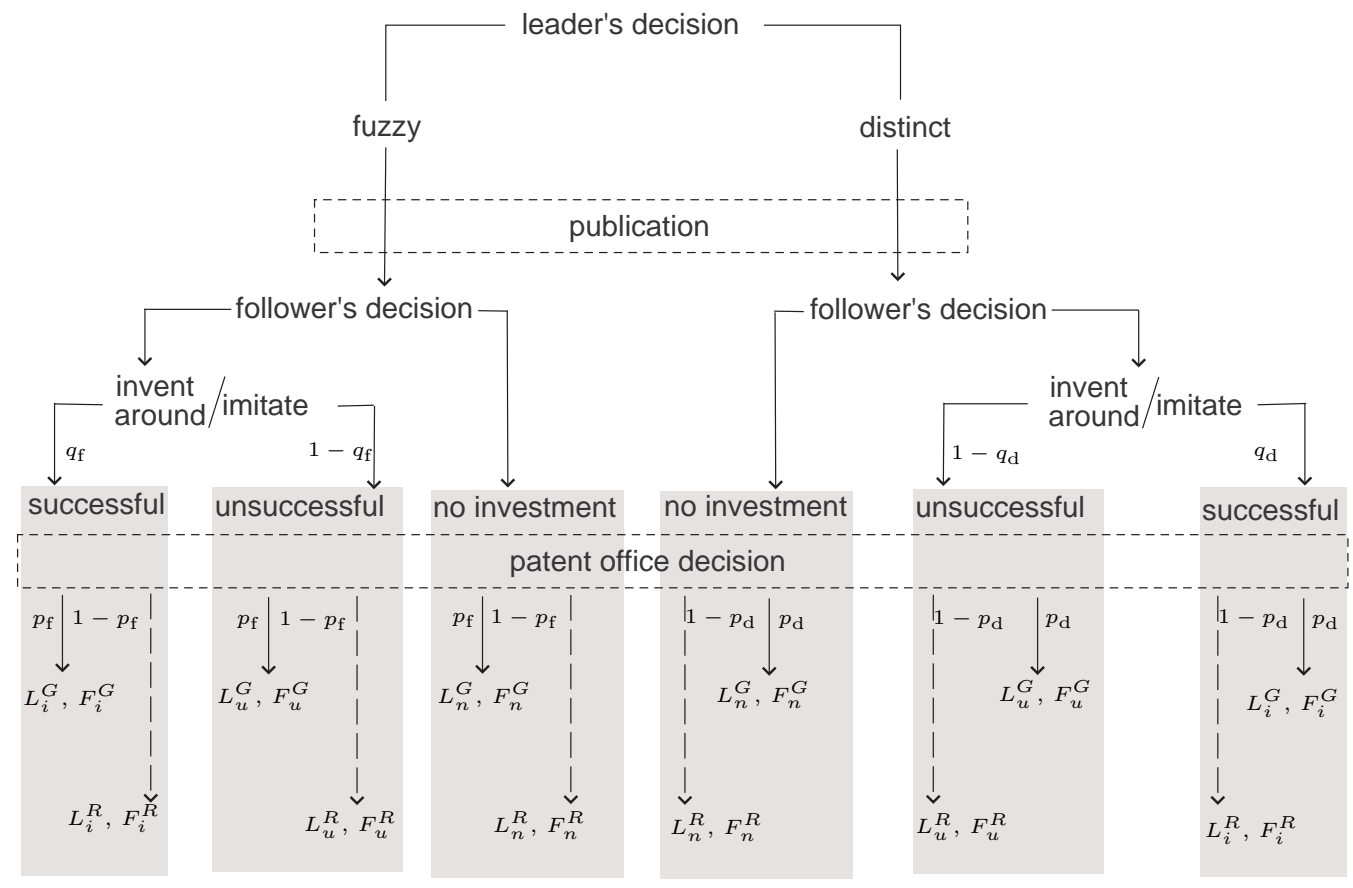

Figure 2: The order of decisions

Regarding the phrasing of his patent, the leader faces the trade-off between a positive and a negative effect of a fuzzy patent specification. On the one hand, fuzziness yields two benefits for the leader: (i) it increases research costs for the follower from $c_{d}$ to $c_{f}$ and (ii) it decreases the probability that the follower successfully invents around the patent from $q_{d}$ to $q_{f}$, i.e. fuzziness mitigates the threat of market entry. This is due to the fact that the innovative knowledge contained in the patent specification can be straightforwardly implemented by a rival firm if the phrasing of the patent is distinct. With a fuzzy patent, inventing around is more costly and failure of inventing around or imitating is more likely as a follower firstly needs to concretize the unspecific description of the innovation. On the other hand, obscuring the patent specification bears a higher risk of a rejection of the patent application: in the case of a fuzzy patent specification, a patent will only be granted with a lower probability $p_{f}<p_{d}$.

We solve the game by backward induction. On the final stage, payoffs are realized. On the second stage, the follower after observing the publication of the patent application decides on his research investment. On stage 1, the leader decides about the specificity used in the formulation of his patent. 


\subsection{Realization of payoffs}

In Figure 2, the alternative revenues of the leader and the follower are given by $L_{a}^{B}$ and $F_{a}^{B}$ where the lower index $a=i, u$ states whether the follower successfully imitated/invented around $(i)$, whether he was unsuccessful $(u)$ or whether he refrained from investing in the first place $(n)$. The upper index $B=G, R$ represents the cases that the patent is granted $(G)$ or rejected $(R)$. Note that only for the leader these revenues correspond to the profits. To calculate the actual profits for the follower in the case that he invests in research, costs $c_{s}$, $s=d, f$ have to be subtracted from the revenue. While the cases (1) inventing around and (2) imitation are not explicitly considered as alternative strategies in our model, they are nevertheless both included subject to a proper interpretation of the payoffs. In case (1), the follower enters the market with a variant of the innovation that does not infringe the issued patent, such that the follower does not have to pay licensing royalties to the leader. ${ }^{9}$ To realize positive payoffs, in this case the leader also enters the product market. Thus, in the case of successful imitation/inventing around the payoffs $L_{i}^{G}$ and $F_{i}^{G}-c_{s}$ with $s=d, f$ are the profits realized in a duopoly with differentiated products (these scenarios are represented by rectangles 1 and 6, counting from the lower left corner, in Figure 2 ). In case (2), the follower has to pay licensing royalties to the leader. Then the patentee does not need to enter the product market to collect positive payoffs, $L_{i}^{G}$ would be the licensing royalties he earns. A different strategy for the leader could also be to commercialize the innovation himself and collect licensing royalties at the same time. His payoff $L_{i}^{G}$ then would consist of the profits in a differentiated duopoly plus licensing royalties whereas the follower's payoff $F_{i}^{G}-c_{s}$ with $s=d, f$ consists of the duopoly profits minus licensing fees.

Staying in rectangles 1 and 6, we next discuss the situation where the patent is not granted. Here we implement the strong assumption that the leader realizes zero profits whenever the patent is rejected, i.e. $L_{i}^{R}=0, L_{u}^{R}=0$ and $L_{n}^{R}=$ 0 . Note that this does not mean that the leader will never realize profits from his innovation. We simply assume that he will not realize them in the time period which we consider, which ends directly after the granting decision. As mentioned, the patenting process de facto is an interaction process so that it is quite improbable that a patent applicant is completely surprised to find his patent rejected. More probably, he will already have developed a strategy to cope with this situation. This could, for example, be a new patent application with modified claims or the division of the innovation into more than one patent application. In any case, we assume that he postpones commercializing the innovation. At the same time, the follower who successfully invented around or imitated will enter and collect positive profits $F_{i}^{R}-c_{s}$ with $s=d, f$. Finally, in the case of a patent grant when the follower is either unsuccessful or chooses not to enter in the first

\footnotetext{
${ }^{9}$ The fact that the follower used the patent as knowledge input for his research is exempted from patent protection by the research use exemption.
} 
place (rectangles 2 to 5 in Figure 2), the patentee enters the market and earns positive profits $L_{u}^{G}$ and $L_{n}^{G}$ respectively.

\subsection{The follower's decision}

On the second stage, the follower decides whether to invent around/imitate the patent or not. We obtain his decision given either a fuzzy or a distinct patent by simply comparing his expected payoffs in both cases. Given a fuzzy patent specification his expected profit if he chooses to invest in research to invent around/imitate is given by

$$
q_{s}\left[p_{s}\left(F_{i}^{G}-c_{s}\right)+\left(1-p_{s}\right)\left(F_{i}^{R}-c_{s}\right)\right]+\left(1-q_{s}\right)\left(-c_{s}\right) \text { with } s=f, d,
$$

whereas his expected profit given the alternative of no investment is null. Thus, the follower will invest in research whenever his expected profit is positive. Solving this condition for the probability of a patent grant yields the critical condition

$$
p_{s}^{F} \equiv \frac{F_{i}^{R}-c_{s} / q_{s}}{F_{i}^{R}-F_{i}^{G}}>p_{s} \text { with } s=f, d .
$$

To obtain economically reasonable results we assume $c_{s} / F_{i}^{R}<q_{s}<c_{s} / F_{i}^{G}, s=$ $d, f$. Whenever the granting probability is lower than this critical threshold it is profitable for the follower to invest in inventing around/imitating the potential patent. The two critical conditions for $s=f, d$ constitute four alternative possible cases subject to the parameter values of $p_{f}$ and $p_{d}$. These cases are depicted in Figure 3. Note that the angle bisector defines the area where the granting probabilities $p_{d}$ and $p_{f}$ are equal. Therefore, all parameter values in the area below the angle bisector can be interpreted as reflecting a high examination quality as here the granting probability is higher with a distinct patent, $p_{d}>p_{f}$, while the area above the angle bisector reflects a low examination quality as here $p_{f}>p_{d}$ holds. 


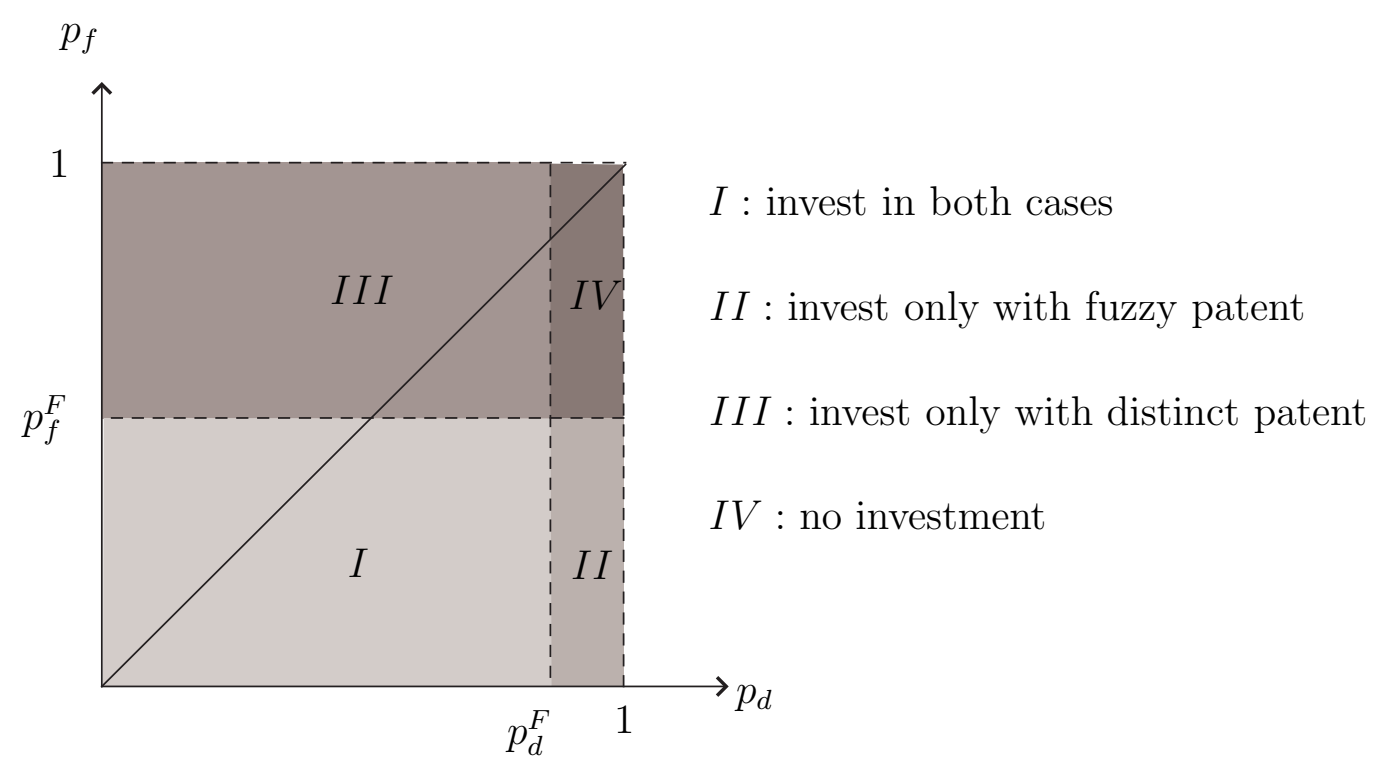

Figure 3: The follower's decision to invest

In area $I, p_{s}<p_{s}^{F}, s=f, d$, holds so that the follower invests in both cases, fuzzy or distinct patent. In area $I I$, only $p_{f}<p_{f}^{F}$ holds while $p_{d}>p_{d}^{F}$ meaning that investing in research is only profitable with a fuzzy patent. In area $I I I$, the situation is reversed, here $p_{d}<p_{d}^{F}$ holds while $p_{f}>p_{f}^{F}$. Therefore, the follower only chooses to invest when the leader uses a distinct language in his patent specification. In area $I V$, both conditions are violated so that it is never profitable for the follower to invest.

\subsection{The leader's decision}

Given these possible scenarios, the leader decides how to phrase his patent on the first stage of the game (see Figure 4). If the exogenous parameters $p_{d}$ and $p_{f}$ are such that case $I$ results, the comparison of the expected profit with a fuzzy or a distinct patent specification gives us the condition

$$
q_{f} p_{f} L_{i}^{G}+\left(1-q_{f}\right) p_{f} L_{u}^{G}>q_{d} p_{d} L_{i}^{G}+\left(1-q_{f}\right) p_{f} L_{u}^{G}
$$

for the advantageousness of a fuzzy patent. Solving this condition for $p_{f}$ yields the critical threshold

$$
p_{f}>p_{f}^{I} \equiv p_{d} \frac{L_{u}^{G}-q_{d}\left(L_{u}^{G}-L_{i}^{G}\right)}{L_{u}^{G}-q_{f}\left(L_{u}^{G}-L_{i}^{G}\right)} .
$$


For all granting probabilities above this threshold a fuzzy patent is profitable for the leader. As the curve describing $p_{f}^{I}$ is linear in $p_{d}$ and we have $\left.p_{f}^{I}\right|_{\left(q_{d}=1\right)}<1$, it lies below the angle bisector and we can state

Lemma 1 In case I, the leader has the incentive to choose a fuzzy patent specification as long as the resulting decrease of the granting probability is not too high.

Note that in case $I$ the follower enters even with a fuzzy patent. Obscuring the patent is nevertheless profitable for the leader as it increases his expected profit by decreasing the follower's probability of success. Figure 4 shows how the critical threshold divides area $I$ into the sub-areas $I a$ and $I b$. If ceteris paribus the effect of a fuzzy patent specification on the usability of information for the follower increases (the probability of successful research, $q_{f}$, decreases) the critical threshold $p_{f}^{I}$ decreases. This would be reflected by a downward movement of the bold black curve in area $I$ of Figure 4, such that the striped area Ia grows larger: fuzzy patents become profitable for a larger range of parameter values. If ceteris paribus the granting probability for a distinct patent, $p_{d}$, increases, the critical threshold increases moving the curve in Figure 4 upward, such that the striped area $I a$ decreases: the use of fuzzy patents becomes less profitable.

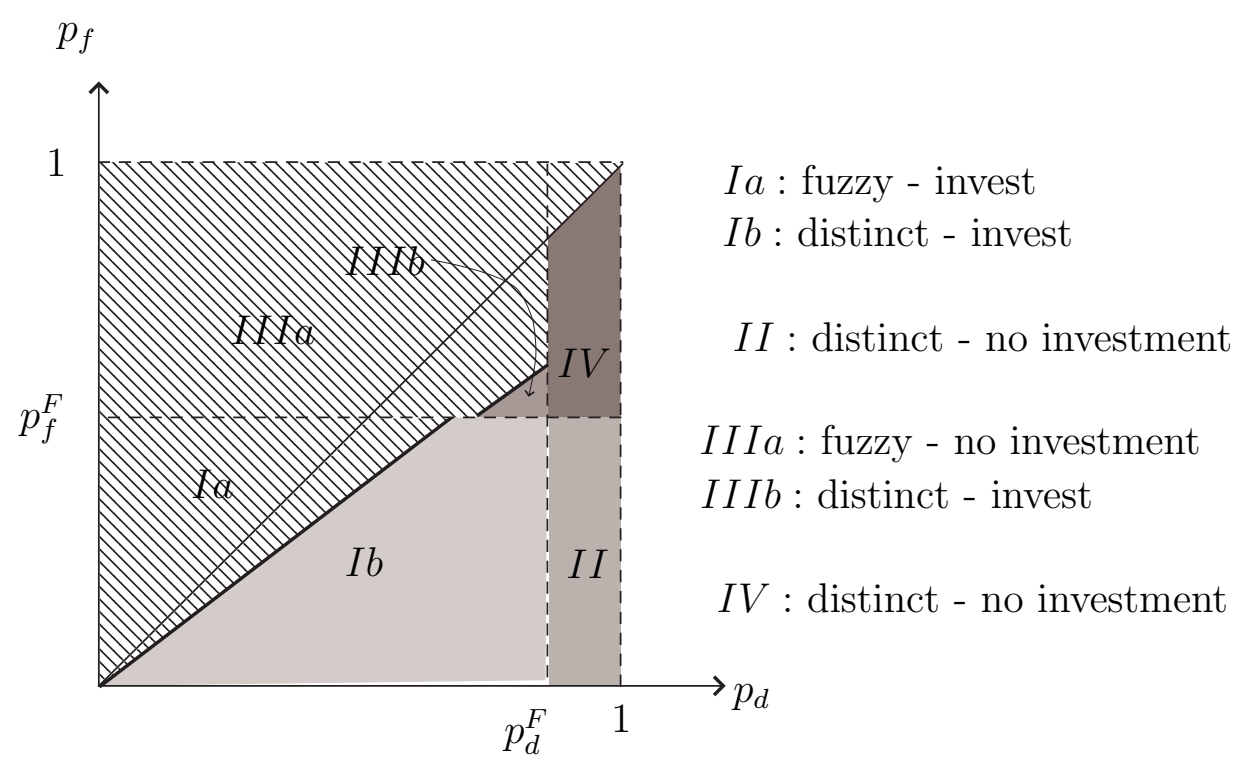

Figure 4: The leader's decision between a fuzzy or a distinct patent 
In case $I I$, the follower only invests given a fuzzy patent. The critical condition for the profitability of a fuzzy patent changes to

$$
q_{f} p_{f} L_{i}^{G}+(1-q f) p_{f} L_{u}^{G}>p_{d} L_{u}^{G} .
$$

Solving this condition for $p_{f}$ it is straightforward that it can never be fulfilled due to the fact that case $I I$ only occurs if examination quality is high, i.e. $p_{d}>p_{f}$. Thus we have

Lemma 2 In case II, the leader always chooses a distinct patent specification.

In case $I I I$, the follower only invests if the patent specification is distinct, that is, whenever the leader chooses a fuzzy patent, the follower will refrain from investing in research. This adds an additional strategic component to the choice of the patent language: by obscuring his patent the leader can possibly inhibit an imitation attempt of the follower. The critical condition comparing the expected profits with a fuzzy and a distinct patent yields

$$
p_{f}>p_{f}^{I I I} \equiv p_{d} \frac{L_{u}^{G}-q_{d}\left(L_{u}^{G}-L_{i}^{G}\right)}{L_{u}^{G}} .
$$

If the probability that the follower's investment is successful, $q_{d}$, is high enough, this threshold divides area $I I I$ into two sub-areas, see Figure 4 . In area IIIa, it is profitable for the leader to obscure his patent, as then the follower refrains from investing in imitation. If however the difference between the granting probabilities is high, such that a distinct patent yields a sufficiently greater probability that the patent will be granted, the strategic aspect of discarding the follower's research investment is undermined by the risk of rejection: In area $I I I b$, the leader chooses a distinct patent language and thus accommodates the research investment of his rival who will invest due to the fact that inventing around/imitating successfully has a high probability. Whenever $q_{d}$ is too low, area $I I I b$ vanishes and choosing a fuzzy patent is always profitable as then the follower refrains from investing. Summarizing we state

Lemma 3 In case III, a fuzzy patent specification can discard the follower's research attempts. Given a high success probability of the follower, $q_{d}$, the leader has the incentive to choose a fuzzy patent specification as long as the resulting decrease of the granting probability is not too high. Given a low success probability, the leader always chooses a fuzzy patent specification.

Finally, in area $I V$ where the follower never invests it is obviously profitable for the leader to choose a distinct patent specification for high examination quality, $q_{d}>q_{f}$ and fuzzy patent language for low examination quality $q_{d}<q_{f}$. This gives us

Lemma 4 In case $I V$ the leader chooses a distinct patent specification given $q_{d}>q_{f}$ and a fuzzy patent specification given $q_{d}<q_{f}$. 
The leader has a strong incentive to strategically use fuzziness in his patent specification whenever the probability that the patent will nevertheless be granted is high. Then, by obscuring the description of the invention the leader has a weapon against the possible market entry of a rival. He can mitigate the threat of entry by imposing an additional hurdle for the follower: the fuzziness of the patent specification.

The driving force between the leader's decision is the quality of patent examination which - within the scope of this simple model - can be interpreted as the difference between the granting probabilities with a distinct and a fuzzy patent specification, $\Delta p \equiv p_{d}-p_{f}$. Facing the decision how to formulate his patent an inventor knows (or at least has a belief) about the examination quality of the patent authorities. In our model setting, he knows on which point in Figure 4 he is "located". Recall that examination quality is highest in the lower right corner and decreases moving to the upper left corner. For a low examination quality, we naturally find that a fuzzy patent specification is always beneficial, but interestingly for a high examination quality (below the angle bisector) it is not necessarily optimal to choose a distinct patent language. Whenever the difference between granting probabilities is not too high, a fuzzy patent yields higher expected profits for the inventor. The following proposition summarizes this central finding.

Proposition 1 A successful inventor has the incentive to obscure his patent specification whenever this does not substantially decrease the probability of a patent grant, i.e. whenever patent examination quality is not too high.

Figure 4 depicts this finding graphically. It is straightforward ${ }^{10}$ that the threshold $p_{f}^{I I I}$ derived earlier lies below $p_{f}^{I}$. The additional strategic component of a fuzzy patent is displayed by the "jump" between the bold lines representing the difference between the critical thresholds $p_{f}^{I}$ and $p_{f}^{I I I}$. This jump draws from the strong impact of the use of a fuzzy patent language on the strategy of the follower in case $I I I$ : His non-investment given a fuzzy patent substantially increases the leader's expected payoff, making the use of an imprecise patent language profitable for a larger range of parameter values. This finding gives us

Proposition 2 If the granting probability is high despite an imprecise patent language, $p_{f}>p_{f}^{F}$, a fuzzy patent can even prevent imitation/inventing around the patent and thereby mitigates the threat of market entry by a rival firm.

Recall that examination quality $\Delta p=p_{d}-p_{f}$ becomes larger when moving to the lower right corner. Therefore, the striped region in area $I I I$ covers a wider range of examination qualities than the striped region in area $I$, reflecting the additional strategic component of a fuzzy patent in case $I I I$. Due to this a fuzzy patent specification is beneficial even if patent examination quality is relatively high, i.e. in such a case even a (small) increase in the quality of patent examination cannot reduce the strategic use of a fuzzy patent language.

\footnotetext{
$\overline{{ }^{10} \text { As obviously }\left.p_{f}^{I I I}\right|_{\left(p_{d}=1\right)}<\left.p_{f}^{I}\right|_{\left(p_{d}=1\right)}}$.
} 


\section{Conclusion}

This paper provides a theoretical model which explains how the degree of specificity of a patent description may be used strategically to limit possible positive effects of patent publication on the research of a rival firm. Earlier studies already hinted to the fact that the patent language might be a harmful factor to disclosure (see Fromer 2009, Seymore 2010, Hall and Harhoff 2012).

We consider the effect of a patentee's decision on how to phrase his patent description using either a distinct or fuzzy patent language. Obscuring the patent specification to limit the technical specificity, on the one hand, decreases the usability of the patent for a follower, which is reflected by an increase of the follower's research costs and by a decrease of his probability of success. On the other hand, a fuzzy patent decreases the probability to get the patent granted. Concluding we find that the obscurement of the patent description may be profitable for an innovator in some cases. We find that for low examination quality it is always beneficial for an inventor to choose a fuzzy patent formulation. For high examination quality, we identify two scenarios in which the fuzzy formulation of a patent yields higher profits than the use of a distinct patent description: $(i)$ If the granting probability despite the use of a fuzzy language is not too high, the follower will invest in inventing around (or imitating) the (applied for) patent despite its impreciseness. The leader nevertheless chooses a fuzzy patent as his expected profit is higher due to the decrease of the follower's probability of success. ( $i i$ ) If the granting probability in case of a fuzzy patent lies above a critical threshold, the competitor does not invest in inventing around or imitating the patent. In this case, a fuzzy patent imposes an effective entry hurdle for the follower.

If we take the common assumption - that a higher level of aggregate R\&D investment results in a faster technological progress - authorities would prefer distinct descriptions (in the presented model with a distinct patent the follower invests in research in three out of four considered cases, while with a fuzzy patent he invests in two out of the four cases). As Seymore 2010 points out a patent application does usually not need to be amended by the proof of a working embodiment or experimentation results. In this respect, our results would suggest that a mandatory requirement of providing such data and information at the time of the patent application may enhance the examination quality and the quality of disclosure. This procedure would be analogous to scientific publications where exact data, measurements etc. must be submitted in order to get published. ${ }^{11}$

\footnotetext{
${ }^{11}$ As a side note to the specificity of pharmaceutical patents: Providing reliable information on the working of the invention would not mean that filing needs to be postponed until the end of the clinical trials. The proof of a working discovery is in the first place not linked neither to its effectiveness nor to its harmlessness with respect to the patients.
} 


\section{Appendix}

\section{Proof of Lemma 3}

The function running through the point $\left(p_{f}^{F}, p_{d}^{F}\right)$ in Figure 4 is given by $p_{d} p_{d}^{F}$. For area $I I I b$ to exist the critical value $p_{f}^{I I I}$ needs to lie above this function. Solving $p_{f}^{I I I}>p_{d} p_{d}^{F}$ for $q_{d}$ we obtain the two solutions

$$
q_{d}^{ \pm} \equiv \frac{2 c_{d} \sqrt{L_{u}^{G}}}{F_{i}^{G} \sqrt{L_{u}^{G}} \pm \sqrt{4 c_{d}\left(F_{i}^{G}-F_{i}^{R}\right)\left(L_{i}^{G}-L_{u}^{G}\right)+F_{i}^{G^{2} L_{u}^{G}}}}
$$

From twice differentiating $p_{f}^{I I I}-p_{d} p_{d}^{F}$ with respect to $q_{d}$ we know that in between these zero points of the curve lies a minimum. Due to its negative denominator, $q_{d}^{-}$is negative, whereas we have $0<q_{d}^{+}<1$. Thus we can state that for $q_{d}>q_{d}^{+}$ the critical condition $p_{f}^{I I I}>p_{d} p_{d}^{F}$ is fulfilled and hence area $I I I b$ exists. 


\section{References}

Bessen, J.: 2005, Patents and the diffusion of technical information, Economics Letters 86, 121-128.

Bessen, J. and Meurer, M.: 2009, Patent Failure: How Judges, Bureaucrats, and Lawyers Put Innovators at Risk, Princeton University Press, Princeton NJ.

Cohen, W. M., Goto, A., Nagata, A. and Walsh, J. P.: 2002, R\&d spillovers, patents and the incentives to innovate in japan and the united states, Research Policy 31, 1349-1367.

Devlin, A.: 2010, The misunderstood function of disclosure in patent law, Harvard Journal of Law \& Technology 23, 401-446.

Fromer, J.: 2009, Patent disclosure, Iowa Law Review 94, 539-596.

Gambardella, A., Harhoff, D. and Nagaoka, S.: 2011, The social value of patent disclosure, Unpublished manuscript, LMU Munich.

Hall, B. H. and Harhoff, D.: 2012, Recent research on the economics of patents, NBER working paper $\mathbf{1 7 7 7 3 .}$

Lemley, M., Lichtman, D. and Sampat, B.: 2005, What to do about bad patents?, Regulation 28, 10-13.

Roin, B.: 2007, The disclosure function of the patent system: or lack thereof, Harvard Law Review 118, 2007-2028.

Seymore, S.: 2010, The teaching function of patents, Notre Dame Law Review 85, 621-669. 